\title{
Surgical Treatment of Pyogenic Spondylitis with the Use of Freeze-Dried Structural Allograft
}

\author{
Seung-Soo Kim, Dong-Ho Kang, Jong-Won Yoon, Hyun Park, \\ Chul-Hee Lee, Soo-Hyun Hwang \\ Department of Neurosurgery, GyeongSang National University School of Medicine, Jinju, Korea
}

\begin{abstract}
Objective: Radical debridement and reconstruction is necessary for surgical treatment of pyogenic spondylitis to control infection and to provide segmental stability. The authors identified 25 patients who underwent surgery for pyogenic spondylitis using freeze-dried structural allograft for reconstruction. This study aimed to evaluate and demonstrate the effectiveness and safety of a freeze-dried structural allograft during the surgical treatment of pyogenic spondylitis.

Methods: From January 2011 to May 2013, we retrospectively reviewed 25 surgically treated patients of pyogenic spondylitis. Surgical techniques used were anterior radical debridement and reconstruction with a freeze-dried structural allograft and instrumentation. In these 25 patients, we retrospectively examined whether the symptoms had improved and the infection was controlled after surgery by evaluating laboratory data, clinical and radiological outcomes. The average follow-up period was 15.7 months (range, 12.2-37.5 months).

Results: The infection resolved in all of the patients and there were no cases of recurrent infection. The mean Visual Analog Scale score was 6.92 (range, 5-10) before surgery and 1.90 (range, 0-5) at the time of the last follow-up. Preoperatively, lower extremity motor deficits related to spinal infection were noted in 10 patients, and they improved in 7 patients after surgery. Follow-up computed tomographic scans were obtained from 10 patients, and osseous union between the vertebral body and the structural allograft was achieved in 2 patients.

Conclusion: The freeze-dried structural allograft can be a safe and effective alternative for surgical treatment of pyogenic spondylitis, and another option for vertebral reconstruction instead of using the other materials.
\end{abstract}

Key Words: Spondylitis · Allografts

\section{INTRODUCTION}

Pyogenic spondylitis constitutes approximately 1 to $7 \%$ of all osseous infections ${ }^{1)}$. In recent years, the incidence of spinal infections has increased, and this disease is now estimated to occur in approximately 1 per 100,000 individuals annually ${ }^{7,16)}$. However, the treatment of this disease is complex and difficult because of disastrous morbidity and mortality due to the associated medical conditions. In addition, because the initial manifestation can be subtle, misdiagnosis or delayed

- Received: March 19, 2014 - Revised: May 2, 2014

- Accepted: May 30, 2014

Corresponding Author: Dong-Ho Kang, MD, PhD

Department of Neurosurgery, GyeongSang National University School of Medicine, 90 Chiram-dong, Jinju, Gyeongsangnam-do 660-702, Korea Tel: +82-55-750-8112, Fax: +82-55-759-0817

E-mail: ns4793@hanmail.net

®This is an Open Access article distributed under the terms of the Creative Commons Attribution Non-Commercial License (http://creativecommons.org/ licenses/by-nc/3.0/) which permits unrestricted non-commercial use, distribution, and reproduction in any medium, provided the original work is properly cited. diagnosis is possible.

Although the mainstay of management is nonsurgical treatment of pyogenic spondylitis, surgical treatment should be considered in case of neurological compromise, spinal instability, significant deformity, or medical treatment failure ${ }^{9,14,18 \text {, }}$ $24,27,28,30)$

While performing surgical treatment, aggressive removal of the infected tissue including the vertebral body, disc, and soft tissue and the use of a structural graft may be required. The structural grafting of a non-living material in pyogenic spondylitis can induce the persistence of infection and reconstruction failure. Therefore, conventional autografts including iliac crest, rib, or fibula were used as a structural graft. However, the use of autografts is limited due to harvesting-related morbidity, structural weakness, and limitation in the supply of a long segment ${ }^{2,4,20)}$. Recently, the authors performed several studies using titanium mesh or fresh-frozen allografts ${ }^{12,14,15 \text {, }}$ $17,21,22,29,31)$. However, the use of titanium mesh in pyogenic spondylitis is not covered by the Korean medical insurance system and a fresh-frozen allograft is not commercialized accor ding to its length; therefore, it is less cost-effective. 
Hence, we used a freeze-dried structural allograft to overcome the drawbacks of previously described materials used for the reconstruction of anterior spinal column in surgical treatment of pyogenic spondylitis.

Herein, we aimed to evaluate and demonstrate the effectiveness and safety of a freeze-dried structural allograft during the surgical treatment of pyogenic spondylitis.

\section{MATERIALS AND METHODS}

From January 2011 to May 2013, 25 patients with pyogenic spondylitis were surgically treated with freeze-dried structural allograft at our hospital. In these 25 patients, we retrospectively examined whether the symptoms had improved and the infection was controlled after surgery.

The diagnosis of pyogenic spondylitis was based on the clinical presentation, laboratory assessments, imaging findings, microbiological assay, and pathological evidence. At the time of the diagnosis, if there were indications for surgery such as neurological compromise, spinal instability, severe pain, and deformity, the patients underwent surgery along with tissue cultures and biopsy. If there were no indications for surgery, antibiotic agents were administered depending on the results of tissue culture for which needle aspiration and biopsy had been performed, and in cases of persistent infection or occurrence of a new neurological deficit, instability, or deformity despite medical management, surgical treatment was performed.

All patients in the study underwent a detailed history taking including spondylitis-related predisposing factors and neurologic examination at the time of admission and immediately before the operation. For evaluating the degree of infection control, we checked the pain and laboratory assessments including C-reactive protein (CRP) and erythrocyte sedimentation rate (ESR). Pain was evaluated using the Visual Analog Scale (VAS) score, and neurological status was checked according to the Frankel grade before surgery and at the time of the last follow-up. Postoperatively, the laboratory assessment and radiographic follow-up were performed periodically. Anteroposterior and lateral plain $\mathrm{x}$-rays were used for follow-up radiologic assessment. In 10 out of the 25 patients, follow-up computed tomographic (CT) scan was performed for detecting osseous union (bone fusion) between the structural allograft and the vertebral body interface.

\section{Surgical Procedure and Postoperative Care}

Some lesions were approached through staged anterior and posterior procedures, and the other lesions were approached through only the anterior procedure.

Thoracic lesions were approached anteriorly through thoracotomy, lesions located in the lumbar region were approached via the retroperitoneal approach, and some lesions involving the thoracolumbar junction were approached via the thoracoabdominal approach. The anterior approach was used, and radical debridement of all infected and necrotic tissues including the infected vertebral body and disc, as well as spinal cord or thecal sac decompression was performed. The corpectomy was extended backwards to the healthy bleeding bone to allow for subsequent bone fusion and tissue healing. Intraoperative tissue culture of the resected bone tissue was performed. Then, a tailored freeze-dried structural allograft filled with cancellous allobone graft with or without autologous rib graft, was placed at the corpectomy site. Then, in order to provide more stability and fix the graft more securely according to the need, we used bicortical anterior vertebral body screws.

In 17 among the total 25 patients, the occurrence of graft subsidence was predicted in some patients due to severe osteoporotic changes in the vertebrae, application of anterior vertebral body screws in the lower lumbar spine was performed in patients who had disturbed iliac crest, and staged posterior instrumentation and posterolateral spinal fusion was performed within 2 weeks after the anterior surgery to gain stability in patients who had involvement of multiple vertebral bodies. All patients received culture-specific intravenous antibiotics for a minimum of 4 to 6 weeks, followed by oral antibiotics until the infection resolved, and they wore external orthosis for 8 to 12 weeks.

\section{RESULTS}

In Table 1, we have summarized the patient data. There were no mortalities and none of the patients were lost to follow-up to conclude remedy. All patients were followed up for more than 12 months. There were 13 males and 12 females, with a mean age of 64.7 years (range, 24 to 76 years). The average follow-up period was 15.7 months (range, 12.2-37.5 months).

We carefully selected patient who would be underwent surgery. If there were no absolute surgical indication previous described, antibiotics were administered and surgical treatment was not performed. In our cases, 17 cases were administered antibiotics firstly before the surgical treatment. Among them, 15 cases were underwent surgery due to poor control of infection and severe relapsing pain, and 2 cases were underwent surgery due to deterioration of neurological status. They administered antibiotics averagely 5.3 weeks preoperatively. The 8 cases which had neurological compromise (3 cases) and 
Table 1. Summary of patients' data

\begin{tabular}{|c|c|c|c|c|c|c|}
\hline $\begin{array}{l}\text { Case } \\
\text { No. }\end{array}$ & $\begin{array}{l}\text { Age(yrs) } \\
\text { /Sex }\end{array}$ & Levels & Predisposing factors & Infectious organism & Approach & $\begin{array}{l}\text { Follow Up } \\
\text { (month) }\end{array}$ \\
\hline 1 & $59 / \mathrm{M}$ & L2-3 & $\begin{array}{l}\text { poor general condition (LC", chronic alcholism), } \\
\text { MRSA }^{* *} \text { bacteremia }\end{array}$ & $\mathrm{MRSA}^{* *}$ & Combined & 37.5 \\
\hline 2 & $59 / \mathrm{M}$ & L3-4 & previous operation, diabetes mellitus & No growth & Retroperitoneal & 22.1 \\
\hline 3 & $74 / F$ & L1-2 & $\begin{array}{l}\text { Infective endocarditis, Streptococcus viridans } \\
\text { bacteremia }\end{array}$ & $\begin{array}{l}\text { Streptococcus } \\
\text { viridans }\end{array}$ & thoracoabdominal & 16.0 \\
\hline 4 & $69 / F$ & $\mathrm{~T} 10$ & previous operation & S. epidermdis & Combined & 18.0 \\
\hline 5 & $63 / \mathrm{M}$ & T5- 10 & $\begin{array}{l}\text { poor general condition (ASO }{ }^{*}, \mathrm{CAD}^{\dagger} \text {, cardiomyopathy, } \\
\text { oral candidiasis, clonorchiasis, pneumonia) }\end{array}$ & No growth & Combined & 32.4 \\
\hline 6 & $67 / F$ & T7-10 & previous operation & Finegoldia magna & Combined & 13.4 \\
\hline 7 & $73 / F$ & T12-L1 & previous operation & No growth & thoracoabdominal & 12.4 \\
\hline 8 & $69 / \mathrm{M}$ & L1-2 & $\begin{array}{l}\text { poor general condition }\left(\mathrm{LC} \|, \mathrm{HCC}^{\|} \text {, splenic infarction, }\right. \\
\left.\text { cardiac thrombi, } \mathrm{CRF}^{\ddagger}\right) \text {, permanent intravenous } \\
\left.\text { catheter-related bacteremia (S. epidermidis }{ }^{\ddagger \ddagger}\right)\end{array}$ & S. epidermdis & thoracoabdominal & 12.3 \\
\hline 9 & $69 / \mathrm{M}$ & L4-5 & previous operation & Aspergillus & Combined & 13.6 \\
\hline 10 & $76 / \mathrm{M}$ & L4-5 & previous operation & No growth & Combined & 17.8 \\
\hline 11 & $66 / F$ & T9-12 & None & No growth & Combined & 11.3 \\
\hline 12 & $70 / \mathrm{M}$ & L1-2 & $\begin{array}{l}\text { previous operation, diabetes mellitus, S. epidremidis }{ }^{\sharp} \\
\text { bacteremia }\end{array}$ & S. epidermidis & Retroperitoneal & 13.7 \\
\hline 13 & $71 / \mathrm{M}$ & L1 & $\begin{array}{l}\text { rheumatoid arthritis, long-term steroid use, Knee OP } \\
\text { site infection, S. aureus }{ }^{\dagger+} \text { bateremia }\end{array}$ & S. aureus $^{\dagger \dagger}$ & thoracoabdominal & 12.8 \\
\hline 14 & $69 / F$ & L3-5 & previous operation & S. aureus ${ }^{\dagger \dagger}$ & Combined & 12.3 \\
\hline 15 & $73 / \mathrm{M}$ & T12-L1 & previous operation & No growth & Combined & 13.5 \\
\hline 16 & $24 / M$ & L5-S1 & previous operation & Enterobacter cloacae & Combined & 12.2 \\
\hline 17 & $60 / F$ & L3-4 & previous operation & S. aureus $^{\dagger \dagger}$ & Combined & 12.3 \\
\hline 18 & $72 / F$ & L5-S 1 & previous operation & Enterococcus faecium & Combined & 14.2 \\
\hline 19 & $32 / M$ & L2-L5 & previous operation & S. epidermidis ${ }^{\sharp \ddagger}$ & Retroperitoneal & 13.8 \\
\hline 20 & $71 / \mathrm{M}$ & $\mathrm{L} 1$ & previous operation & $\mathrm{CNS}^{\S}$ & Combined & 13.2 \\
\hline 21 & $69 / F$ & L3-4 & previous acupuncture (root block) & $\mathrm{CNS}^{\S}$ & Combined & 12.3 \\
\hline 22 & $67 / F$ & L3-4 & previous operation, diabetes mellitus & Escherichia coli & Combined & 13.2 \\
\hline 23 & $65 / F$ & L4-5 & liver abscess, deep vein thrombosis & $\begin{array}{l}\text { Klebsiella } \\
\text { pneumoniae }\end{array}$ & Combined & 12.6 \\
\hline 24 & $72 / F$ & T9-10 & previous operation & S. aureus ${ }^{\dagger \dagger}$ & transthoracic & 13.0 \\
\hline 25 & $59 / \mathrm{M}$ & L3-4 & previous operation, diabetes mellitus & S. aureus ${ }^{\dagger \dagger}$ & Combined & 16.4 \\
\hline
\end{tabular}

severe pain (5 cases) were performed surgery initially.

\section{Predisposing Factors for Pyogenic Spondylitis}

Many patients (18 cases) had a history of previous spinal operation or procedure such as interbody fusion, instrumentation, discectomy, vertebroplasty, or paravertebral acupuncture. At the time of the diagnosis of spondylitis, 5 patients already had other infections that can cause spondylitis by hematogenous spread. In 10 patients, other poor general condition- related diseases, such as uncontrolled diabetes mellitus, chronic alcoholism, liver disease, chronic renal failure, or long-term use of steroids, were confirmed to be the predisposing factors for pyogenic spondylitis. In one patient with chronic osteomyelitis confirmed by pathological examination, there was no identifiable predisposing factor.

\section{Microbiology}

The results of tissue culture obtained preoperatively by nee- 
Table 2. Laboratory and clinical outcomes

\begin{tabular}{|c|c|c|c|c|c|c|c|c|}
\hline Case No. & $\begin{array}{c}\text { Pre-OP§ ESR } \\
(\mathrm{mm} / \mathrm{hr})\end{array}$ & $\begin{array}{c}\text { Pre-OP§ CRP* } \\
(\mathrm{mg} / \mathrm{L})\end{array}$ & $\begin{array}{c}\text { Pre-OP§ VAS" } \\
\text { score }\end{array}$ & $\begin{array}{l}\text { Pre-OP§ Frankel } \\
\text { grades }\end{array}$ & $\begin{array}{c}\mathrm{F} / \mathrm{U}^{\ddagger} \mathrm{ESR}^{\dagger} \\
(\mathrm{mm} / \mathrm{hr})\end{array}$ & $\begin{array}{c}\mathrm{F} / \mathrm{U}^{\ddagger} \mathrm{CRP}{ }^{*} \\
(\mathrm{mg} / \mathrm{L})\end{array}$ & $\begin{array}{c}\text { F/ } \mathrm{U}^{\ddagger} \text { VAS" } \\
\text { score }\end{array}$ & $\begin{array}{c}\mathrm{F} / \mathrm{U}^{\ddagger} \\
\text { Frankel grades }\end{array}$ \\
\hline 1 & 101 & 38.7 & 7 & E & 4 & 0.3 & 0 & $\mathrm{E}$ \\
\hline 2 & 108 & 9 & 8 & E & 71 & 1.3 & 2 & $E$ \\
\hline 3 & 48 & 111.3 & 6 & D & 7 & 0.3 & 3 & $\mathrm{E}$ \\
\hline 4 & 37 & 3.8 & 7 & $E$ & 20 & 3.5 & 0 & E \\
\hline 5 & 114 & 196.2 & 10 & D & 18 & 27.1 & 0 & D \\
\hline 6 & 30 & 36.6 & 7 & C & 14 & 0.9 & 1 & $E$ \\
\hline 7 & 36 & 4.3 & 5 & $E$ & 19 & 1.6 & 0 & $E$ \\
\hline 8 & 33 & 19.2 & 6 & $\mathrm{E}$ & 4 & 18.7 & 2 & $\mathrm{E}$ \\
\hline 9 & 40 & 49.6 & 6 & B & 8 & 2 & 1 & C \\
\hline 10 & 86 & 47.2 & 7 & $E$ & 35 & 0.2 & 2 & $\mathrm{E}$ \\
\hline 11 & 25 & 138.1 & 5 & $E$ & 39 & 5.6 & 0 & E \\
\hline 12 & 30 & 101 & 6 & C & 32 & 4.85 & 3 & D \\
\hline 13 & 74 & 64.6 & 7 & D & 23 & 29 & 1 & $\mathrm{E}$ \\
\hline 14 & 115 & 167 & 8 & D & 10 & 0.9 & 2 & $\mathrm{E}$ \\
\hline 15 & 36 & 48.4 & 6 & $\mathrm{E}$ & 4 & 0.9 & 2 & $\mathrm{E}$ \\
\hline 16 & 20 & 44.1 & 7 & $E$ & 6 & 2.9 & 1 & $\mathrm{E}$ \\
\hline 17 & 88 & 74.3 & 6 & B & 15 & 0.3 & 3 & D \\
\hline 18 & 67 & 49.2 & 8 & C & 3 & 0.8 & 3 & C \\
\hline 19 & 50 & 50.6 & 7 & $\mathrm{E}$ & 4 & 2.8 & 2 & $\mathrm{E}$ \\
\hline 20 & 51 & 150.1 & 6 & $E$ & 9 & 0.5 & 1 & $\mathrm{E}$ \\
\hline 21 & 120 & 54.5 & 7 & $E$ & 16 & 1.2 & 4 & $\mathrm{E}$ \\
\hline 22 & 44 & 142.7 & 7 & C & 2 & 13.2 & 2 & C \\
\hline 23 & 96 & 157.1 & 9 & $\mathrm{E}$ & 23 & 0.7 & 3 & $\mathrm{E}$ \\
\hline 24 & 75 & 68.4 & 8 & $\mathrm{E}$ & 3 & 0.7 & 4 & E \\
\hline 25 & 19 & 5.4 & 7 & B & 2 & 0.3 & 5 & B \\
\hline
\end{tabular}

dle aspiration or during surgery were collected from all patients. The most common pathogenic organism was Staphylococcus aureus, which was identified in 6 patients (24.0\%), followed by Staphylococcus epidermidis (4 cases) and coagulase-negative Staphylococcus ( 2 cases). In six patients with acute or chronic osteomyelitis confirmed by pathological examination, negative cultures were obtained.

\section{Laboratory Assessment}

Blood tests were performed at the time of the diagnosis, immediately after the surgery, and periodically thereafter. Laboratory assessment included complete blood count, blood culture, ESR, and CRP, and follow-up blood tests such as ESR and CRP were conducted periodically for evaluating the degree of infection control.

The ESR averaged $61.72 \mathrm{~mm} / \mathrm{hr}$ (range, 19-120 mm/hr, normal range: $0-9 \mathrm{~mm} / \mathrm{hr}$ ) before surgery and most of patient's ESR were reduced significantly within 2 weeks after surgery. And gradual decline was estimated at 4, 8, 12 weeks and $6^{\text {th }}$ month follow up (Table 2). Lastly follow-up mean ESR was 15.64 $\mathrm{mm} / \mathrm{hr}$ (range, $2-71 \mathrm{~mm} / \mathrm{hr}$ ). The mean CRP was $73.26 \mathrm{mg} / \mathrm{L}$ (range, $3.8-196.2 \mathrm{mg} / \mathrm{L}$, normal range: $0-5 \mathrm{mg} / \mathrm{L}$ )) before surgery and it also reduced significantly within 2 weeks after surgery. And gradual reduction was estimated during follow up period. Lastly mean CRP followed was $4.82 \mathrm{mg} / \mathrm{L}$ (range, 0.3-29 mg/L). All patients showed a decrease in ESR and CRP. In 2 patients, the preoperative CRP was within the normal range $(0-5 \mathrm{mg} / \mathrm{L})$ and these patients were diagnosed with chronic osteomyelitis by pathological examination. In patients with poor general conditions or other underlying diseases, the ESR was less likely to return to a completely normal level.

\section{Clinical Outcomes}

All patients had a back pain and 14 patients (56\%) had symptoms of radiculopathy. Postoperatively, all patients showed an improvement in pain. The mean VAS score was 6.92 (range, 5-10) before surgery and 1.90 (range, $0-5$ ) at the time of the last follow-up. The mean improvement in VAS score 
was 5.02 .

In the preoperative assessment, lower extremity motor deficits were noted in 11 patients, but the neurologic status was not related to the spinal infection in one case. Preoperative Frankel grades in 10 patients who had lower extremity weakness related to spinal infection were grade $\mathrm{B}$ in 2 patients, grade $\mathrm{C}$ in 4 patients, and grade $\mathrm{D}$ in 4 patients. After surgery, Frankel grade improved in 7 patients, and 4 among these 7 patients recovered completely.

There was no recurrence of infection in the same spinal segment, but a new episode of discitis in a remote spinal segment due to previous spondylitis occurred in one patient, who had poor general condition-related diseases such as chronic alcoholism and liver cirrhosis. Other perioperative complications include superficial wound dehiscence (2 patients), side effect of antibiotics (2 patients), and postoperative pneumonia (1 patient).

\section{Radiographic Results}

Anteroposterior and lateral plain X-rays were used for periodic follow-up assessment of patients. We assessed the overall alignment, graft and hardware integrity, and evidence of infection such as bone erosion, persistent radiolucent lines at the bone-graft interface, or progressive severe kyphotic changes. There were no cases of graft failure, such as fracture, migration, or expulsion of implanted allograft, and no evidence of recurrent infection. The degree of kyphosis or loss of lordosis of the involved segment was measured preoperatively and postoperatively by using the Cobb's method. The average segmental kyphosis or loss of lordosis was 22.08 degrees (range,
22-67.9 degrees) preoperatively. Immediately after surgery, on average, the mean angle was improved by about $7.64^{\circ}$ in all patients, and the degree of postoperative improvement in the segmental angle in the last follow-up plain images was $4.60^{\circ}$.

In 10 of the 25 patients, follow-up CT scan was performed at the mean 16.4-month follow-up. Among these patients, osseous union (bone fusion) between the structural allograft and the vertebral body interface was achieved in only 2 patients, who underwent a CT scan at 24 months and 36 months after the surgery, respectively. The other 8 patients who underwent a CT scan within 18 months of surgery did not show complete bone fusion between the structural allograft and the vertebral body interface. However, bone fusion between the cancellous allograft filling in the structural allograft and the vertebral body was demonstrated in the CT scans of all the 10 patients.

\section{Case Illustrations}

Case 16. A 24-year-old male patient transferred from the local hospital and complained of severe back and leg pain (Fig. 1). He had a history of previous L5-S1 discectomy and magnetic resonance images (MRI) suggest L5-S1 discitis. The ESR and CRP at the visit of our institute were $20 \mathrm{~mm} / \mathrm{hr}$ and $44.1 \mathrm{mg} / \mathrm{L}$, respectively. He complained of aggravating back and leg pain despite antibiotic treatment without bacterial identification for 6 weeks in the local clinic and the CRP value was not controlled. On the follow-up MRI and CT scan, spondylitisprogressed to L5 and S1 vertebral body and bony destruction was exacerbated. We thought infection is not controlled and persistent, that is, treatment failure, surgical treat-
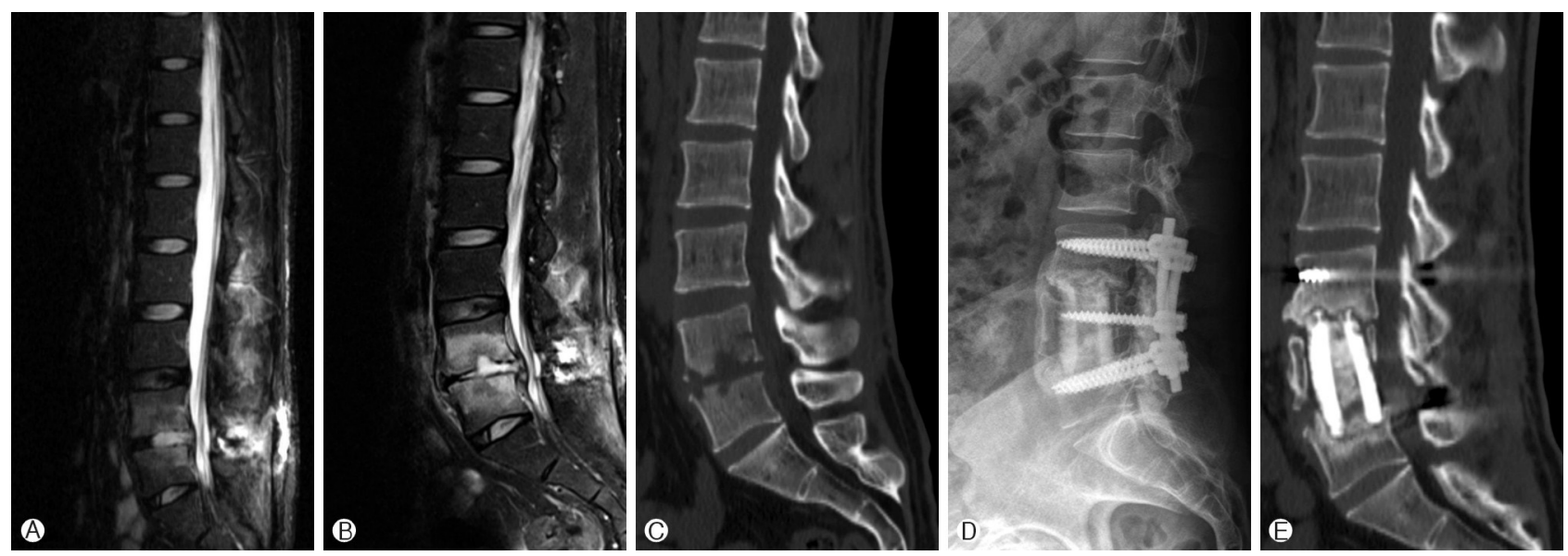

Fig. 1. Case 16. Magnetic resonance images of local hospital (A) suggest L5-S1 discitis. On the follow-up magnetic resonance images (B) and computed tomographic scan (C) after antibiotic treatment in the local clinic, spondylitis progressed to L5 and S1 vertebral body and bony destruction was exacerbated. Postoperative follow-up lumbar plain X-ray (D) and computed tomographic scan (E) taken at 12 months did not show graft failure. But, bone fusion was not yet achieved. 

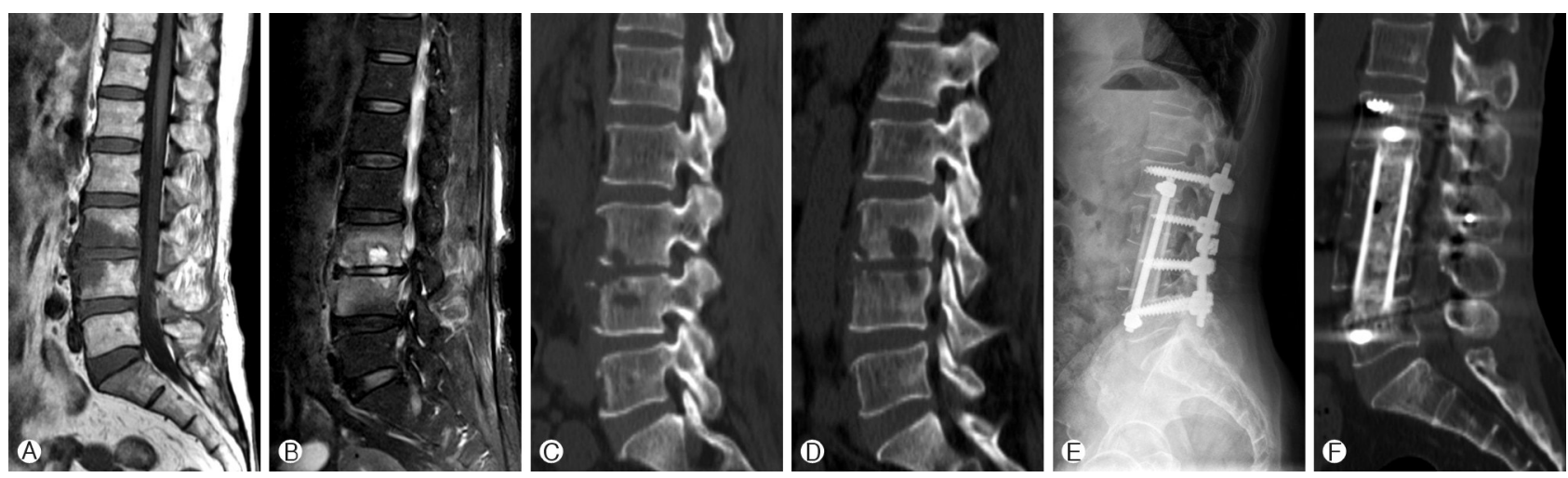

Fig. 2. Case 21. Initial magnetic resonance images (A) suggest spondylodiscitis of $L 3$ and $L 4$. On the follow-up magnetic resonance images (B) and computed tomographic scan (C and D), severe destruction of end plate and vertebral body at $L 3$ and 4 and paravertebral and epidural inflammation worsened than initial images. Postoperative follow-up lumbar plain $X$-ray (E) and computed tomographic scan (F) taken at 12 months show no graft problem and an ongoing bone fusion between the structural allograft and the vertebral body interface.

ment was performed. The anterior radical debridement of all infected and necrotic tissues including the infected vertebral body and soft tissues and anterior column reconstruction with freeze-dried structural allograft and staged posterior instrumentation were performed. Intraoperatively, upper portion of L5 vertebral body showed granulated change and no visible the healthy bleeding bone, therefore the corpectomy was extended to L5 totally to allow for subsequent bone fusion. Postoperative follow-up lumbar plain X-ray and CT scan taken at 12 months did not show graft failure. But, bone fusion was not yet achieved.

Case 21. A 69-year-old female patient complained of severe back pain. The patient had a history of previous spinal nerve root block in the lumbar spine (Fig. 2). The ESR and CRP at the time of hospital visit were $132 \mathrm{~mm} / \mathrm{hr}$ and $45.2 \mathrm{mg} / \mathrm{L}$, respectively. Initial MRI suggests spondylodiscitis of L3 and L4. Antibiotics were administered depending on the results of tissue culture for which needle aspiration. Back pain was quite improved and the CRP value was showed a decrease trend to begin with, but she complained of more deteriorating back pain and left lower extremity radiculopathic pain which had never been seen before, and the CRP value was elevated to $54.5 \mathrm{mg} / \mathrm{L}$ at the time of 4 weeks after the antibiotics administration. On the follow-up MRI and CT scan, severe destruction of end plate and vertebral body at L3 and 4 and paravertebral and epidural inflammation worsened than initial images. The anterior radical debridement of infected and necrotic tissues including the infected vertebral body and soft tissues and vertebral column reconstruction with freeze-dried structural allograft and staged posterior instrumentation were performed. Intraoperatively, residual upper portion of L3 vertebral body and lower portion of L4 vertebral body after corpec- tomy showed yellowish-granulated change and no visible the healthy bleeding bone, therefore the corpectomy was extended to L3 and 4 totally to allow for good fusion bed. Postoperative follow-up lumbar plain X-ray and CT scan taken at 12 months show no graft problem and an ongoing bone fusion between the structural allograft and the vertebral body interface. Bone fusion between the cancellous allograft filling in the structural allograft and the vertebral body was also observed on the CT scan.

\section{DISCUSSION}

In most cases of pyogenic spondylitis, conservative treatment with intravenous antibiotics and external immobilization is the first choice ${ }^{14,24,28,30}$. However, in patients whose infection is resistant to antibiotic therapy and who have major bone destruction, neurological impairment, spinal deformity and severe pain, surgical treatment with anterior debridement and bone grafting is indicated ${ }^{9,18,27)}$.

Bone grafting is a common procedure in spine surgery. In the surgery for pyogenic spondylitis, bone grafting tactics not only aim at bone fusion, but also at structural reconstruction including mechanical strength. Bone fusion, osseous union concomitant with bone formation, requires three essential components: osteogenic, osteoinductive and osteoconductive factors. Also, mechanical strength is an important factor that should be considered for structural supports. From this perspective, autologous cortical bone, which is less biologically active than autologous cancellous bone in terms of bone fusion but more stable against mechanical force, is considered as the gold standard grafting material for spinal reconstruction after 
anterior debridement of infected vertebral body. However, its harvest is associated with significant donor-site morbidity and its supply is too limited for providing a long segment suitable for reconstruction after radical debridement spanning multiple segments of vertebral bodies ${ }^{2,4,20)}$.

Besides using the autograft for bone fusion and structural reconstruction, titanium mesh or structural allograft filled with crushed cancellous autobone or allobone graft has been shown to be effective in achieving bone fusion and structural reconstruction in traumatic, pathologic, and deformity lesions ${ }^{10,34,35)}$. However, in cases of spondylitis, the use of titanium mesh and structural allograft remains controversial because of the risk of persistent or recurrent infection related to a devitalized graft and spinal instrumentation.

Despite these concerns, recent reports have demonstrated the effectiveness and safety of a titanium mesh in the surgical management of pyogenic spondylitis. In our previous study, all 19 cases of pyogenic spondylitis that were treated with radical debridement of infectious tissue and titanium mesh insertion showed no recurrence of infection and the patients showed definite improvement ${ }^{15)}$. In addition, many studies showed that the titanium mesh can be used as a fusion substitute and for providing structural support in pyogenic spondylitis with good results ${ }^{1214,17,21,22,29)}$. Nevertheless, the use of titanium mesh in pyogenic spondylitis is not covered by the Korean medical insurance system.

An allograft is made from cadaveric bone and it has been traditionally used as a substitute for autogenous graft. The use of cortical allograft as a fusion substitute and for providing structural support in spinal anterior column reconstruction, and not in cases of spondylitis, has been well described. Several authors have demonstrated that the use of cortical allograft for achieving bone fusion and for providing structural support is associated with a high clinical success rate and a low complication rate, as compared with autograft ${ }^{5,19,23,25)}$. But, studies for assessing the control of infection and the clinical outcomes of spondylitis are rare.

A structural allograft used in spine surgery can be prepared in two ways; fresh-frozen or freeze-dried. A fresh-frozen allograft is frozen following its harvest. After being washed in an antibiotic solution, it is cooled to $-70^{\circ} \mathrm{C}$ and stored at that temperature. A freeze-dried allograft undergoes a process called lyophilization. After being washed in an antibiotic solution and cooled to $-70^{\circ} \mathrm{C}$, it is lypophilized i.e. it is dehydrated and vacuum packed to reduce the water content to $<5 \%$, which allows for storage at room temperature. Lypophilization reduces the immunogenicity to a greater extent than freezing only, and lyophilized graft was reported to show almost no immunologic response ${ }^{11)}$.

A study on the use of cortical allograft for anterior column reconstruction after radical debridement of the infected spine is rare. James et al. reported about 47 patients who underwent aggressive removal of the infected and devitalized tissue and reconstruction with fresh-frozen allografts. According to the findings of this study, the use of cortical allograft with aggressive debridement and adjuvant antibiotic therapy is a safe and effective option in cases of spondylitis ${ }^{31}$.

In our study, 25 cases of pyogenic spondylitis were treated with radical debridement of all infected and necrotic tissues including the infected vertebral body and disc and then a freeze-dried structural allograft filled with cancellous allobone graft with or without autologous rib graft was placed at the corpectomy site. We expected that the use of freeze-dried allograft in pyogenic spondylitis may be a safe and effective alternative to fresh-frozen allograft. The reasons why we selected freeze-dried structural allograft as a fusion substitute and for providing structural support were as follows: (1) There is a limited supply of long segment autografts that are suitable for reconstruction after radical debridement spanning multiple segments of vertebral bodies and its harvest is associated with significant donor-site morbidity ${ }^{2,420)}$. (2) The use of titanium mesh in pyogenic spondylitis is not covered by the Korean medical insurance system. (3) While a fresh-frozen allograft is stored as frozen and as a natural long segment and not commercialized according to its length, freeze-dried structural allograft is commercialized according to its length and an allograft of an acceptable length can be selected according to the scope of reconstruction. Hence, freeze-dried allograft is more cost-effective than fresh-frozen allograft. (4) Lypophilization of freeze-dried allograft reduces its immunogenicity to a greater extent than freezing only and lyophilized graft was reported to show almost no immunologic response ${ }^{11)}$. (5) There is a risk of a disease transmission in a patient receiving fresh-frozen allograft, most specifically the risk of transmission of human immunodeficiency virus. To date, there have been four cases of human immunodeficiency virus (HIV) transmission following procedures using fresh-frozen bone allograft, but, no cases of human immunodeficiency virus transmission have been documented following procedures using freeze-dried allograft ${ }^{3,11)}$.

According to the results of our study, cases of pyogenic spondylitis, which were treated with aggressive debridement of all infected and necrotic tissues and freeze-dried structural allograft, showed no recurrence of infection. There was a significant improvement in the patient's symptoms. We did not observe any graft failure or progressive kyphosis. In one patient, a new episode of discitis occurred in a remote spinal segment due to previous spondylitis, but it is difficult to say that the infection had recurred.

An allograft cannot induce bone fusion through osteoge- 
nesis because the number of osteogenic cells is decreased by processing and an allograft does not contain osteogenic cells ${ }^{\text {). }}$. The amount of osteoinductive proteins (BMP; bone morphogenetic proteins) may be decreased further by processing. They are partially preserved in fresh-frozen allograft, but they are destroyed in freeze-dried allograft ${ }^{6,26}$. Therefore, osteoconduction is considered as the major pathway of bone fusion with a freeze-dried allograft. Several studies reported the fusion rate with the use of fresh-frozen structural allograft in the thoracic and lumbar spine. According to Kumar et al., radiographic bone union at a mean 36-month follow-up was noted in $66 \%$ of 32 patients who received a structural allograft in the anterior lumbar spine ${ }^{19)}$. Molinari et al. reported about the 23 patients who underwent anterior thoracic or lumbar fusion with fresh-frozen structural allograft. At a minimum 5 -year follow-up, all grafts achieved bone fusion ${ }^{25)}$.

Due to lack of osteoinductive factors, we expected a lower fusion rate with freeze-dried structural allograft compared to the fusion rate with autograft or fresh-frozen allograft. In fact, in our study, among the 10 patients in whom a follow-up CT scan was obtained at a mean 16.4-month follow-up, only $20 \%$ of patients showed bone fusion between the structural allograft and the vertebral body interface. For overcoming the disadvantage of a low fusion rate with freeze-dried structural allograft, we filled the structural allograft with cancellous allobone graft with or without autologous rib graft. As a result, bone fusion between the allograft filling in the structural allograft and the vertebral body was demonstrated in the CT scans of all the 10 patients.

In addition to the fusion rate, clinical success may depend on the maintenance of structural support. Allograft consists mainly of cortical bone, and its main advantage is providing structural support. Compressive strength of a structural allograft is four to five times higher than that of an autograft ${ }^{36}$. On comparison between the fresh-frozen and freeze-dried allografts, the strength of the allograft is maintained by the freshfreezing process. However, the freeze-drying process, may decrease its mechanical strength. Studies have shown that a freeze-dried allograft has $10-45 \%$ less bending strength and $61 \%$ less torsional strength, but its ability to resist compression is not affected ${ }^{26,33)}$. In spite of this, in our study, there were no cases of graft fracture. We think that posterior instrumentation could have reduced the amount of force applied to the allograft.

As mentioned above, mainstay of management of pyogenic spondylitis is nonsurgical treatment. Many investigators already studied about the efficacy of conservative treatments consisting of administration of antibiotics and immobilization. From point of view on duration of CRP recovered, Fukuda

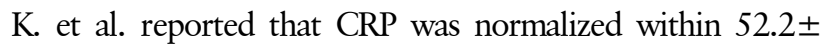

32.5 days when conservatively treated ${ }^{13)}$. In contrast, Suess O. et al. reported that CRP was decreased significantly within 2 week in patients who underwent surgical procedure ${ }^{32)}$. In our cases, most patient's CRP was decreased significantly, about $80 \%$ of them, after surgery within 2 weeks. Additionally, according to several authors, surgical treatment of pyogenic spondylitis has benefits in terms of leading to early ambulation ${ }^{8)}$.

In light of our results of surgical treatment of pyogenic spondylitis, radical debridement of all infected and necrotic tissues and reconstruction using a freeze-dried structural allograft appears to be safe and effective in controlling the infection and improving the symptoms of patients.

There are some limitations to this study. First, a retrospective study design was used. Second, the mean follow-up period for performing the CT scan was inadequate for determining whether bone fusion was achieved and whether the allograft had adequate mechanical strength. Therefore, further investigation for assessing the radiologic outcomes is needed through additional case reports and a long-term follow-up.

\section{CONCLUSION}

The freeze-dried structural allograft is safe, does not influence the infection control, and is effective in vertebral reconstruction due to its mechanical strength during the surgical treatment of pyogenic spondylitis. Hence, it can be another option for vertebral reconstruction instead of using the other materials. However, for assessing bone fusion, further studies including a more extensive cohort and a long-term follow-up are needed.

\section{REFERENCES}

1. Acosta FL, Jr., Chin CT, Quinones-Hinojosa A, Ames CP, Weinstein PR, Chou D. Diagnosis and management of adult pyogenic osteomyelitis of the cervical spine. Neurosurg Focus 17:E2, 2004

2. Arrington ED, Smith WJ, Chambers HG, Bucknell AL, Davino NA. Complications of iliac crest bone graft harvesting. Clin Orthop Relat Res:300-309, 1996

3. Asselmeier MA, Caspari RB, Bottenfield S. A review of allograft processing and sterilization techniques and their role in transmission of the human immunodeficiency virus. Am J Sports Med 21:170-175, 1993

4. Banwart JC, Asher MA, Hassanein RS. Iliac crest bone graft harvest donor site morbidity. A statistical evaluation. Spine (Phila Pa 1976) 20:1055-1060, 1995

5. Bendo JA, Spivak JM, Neuwirth MG, Chung P. Use of the anterior interbody fresh-frozen femoral head allograft in circumferential lumbar fusions. J Spinal Disord 13:144-149, 2000

6. Boden SD, Schimandle JH. Biologic enhancement of spinal fusion. Spine (Phila Pa 1976) 20:113s-123s, 1995 
7. Chelsom J, Solberg CO. Vertebral osteomyelitis at a norwegian university hospital 1987-97: Clinical features, laboratory findings and outcome. Scand J Infect Dis 30:147-151, 1998

8. Digby JM, Kersley JB. Pyogenic non-tuberculous spinal infection: An analysis of thirty cases. J Bone Joint Surg Br 61:47-55, 1979

9. Dimar JR, Carreon LY, Glassman SD, Campbell MJ, Hartman MJ, Johnson JR. Treatment of pyogenic vertebral osteomyelitis with anterior debridement and fusion followed by delayed posterior spinal fusion. Spine (Phila Pa 1976) 29:326-332; discussion 332, 2004

10. Eck KR, Bridwell KH, Ungacta FF, Lapp MA, Lenke LG, Riew $\mathrm{KD}$. Analysis of titanium mesh cages in adults with minimum two-year follow-up. Spine (Phila Pa 1976) 25:2407-2415, 2000

11. Ehrler DM, Vaccaro AR. The use of allograft bone in lumbar spine surgery. Clin Orthop Relat Res:38-45, 2000

12. Fayazi AH, Ludwig SC, Dabbah M, Bryan Butler R, Gelb DE. Preliminary results of staged anterior debridement and reconstruction using titanium mesh cages in the treatment of thoracolumbar vertebral osteomyelitis. Spine J 4:388-395, 2004

13. Fukuda K, Miyamoto H, Uno K, Okada Y. Indications and limitations of conservative treatment for pyogenic spondylitis. J Spinal Disord Tech 27:316-320, 2014

14. Hee HT, Majd ME, Holt RT, Pienkowski D. Better treatment of vertebral osteomyelitis using posterior stabilization and titanium mesh cages. J Spinal Disord Tech 15:149-156; discussion 156, 2002

15. Heo W, Kang DH, Park KB, Hwang SH, Park IS, Han JW. Is titanium mesh cage safe in surgical management of pyogenic spondylitis? J Korean Neurosurg Soc 50:357-362, 2011

16. Jensen AG, Espersen F, Skinhoj P, Rosdahl VT, Frimodt-Moller $\mathrm{N}$. Increasing frequency of vertebral osteomyelitis following staphylococcus aureus bacteraemia in denmark 1980-1990. J Infect 34:113-118, 1997

17. Korovessis P, Repantis T, Iliopoulos P, Hadjipavlou A. Beneficial influence of titanium mesh cage on infection healing and spinal reconstruction in hematogenous septic spondylitis: A retrospective analysis of surgical outcome of twenty-five consecutive cases and review of literature. Spine (Phila Pa 1976) 33:E759-767, 2008

18. Krodel A, Kruger A, Lohscheidt K, Pfahler M, Refior HJ. Anterior debridement, fusion, and extrafocal stabilization in the treatment of osteomyelitis of the spine. J Spinal Disord 12:17-26, 1999

19. Kumar A, Kozak JA, Doherty BJ, Dickson JH. Interspace distraction and graft subsidence after anterior lumbar fusion with femoral strut allograft. Spine (Phila Pa 1976) 18:2393-2400, 1993

20. Kurz LT, Garfin SR, Booth RE, Jr. Harvesting autogenous iliac bone grafts. A review of complications and techniques. Spine (Phila Pa 1976) 14:1324-1331, 1989

21. Liljenqvist U, Lerner T, Bullmann V, Hackenberg L, Halm H, Winkelmann W. Titanium cages in the surgical treatment of severe vertebral osteomyelitis. Eur Spine J 12:606-612, 2003

22. Lu DC, Wang V, Chou D. The use of allograft or autograft and expandable titanium cages for the treatment of vertebral osteomyelitis. Neurosurgery 64:122-129; discussion 129-130, 2009

23. Martin GJ, Jr., Haid RW, Jr., MacMillan M, Rodts GE, Jr., Berkman R. Anterior cervical discectomy with freeze-dried fibula allograft. Overview of 317 cases and literature review. Spine (Phila Pa 1976) 24:852-858; discussion 858-859, 1999

24. McHenry MC, Easley KA, Locker GA. Vertebral osteomyelitis: Long-term outcome for 253 patients from 7 cleveland-area hospitals. Clin Infect Dis 34:1342-1350, 2002

25. Molinari RW, Bridwell KH, Klepps SJ, Baldus C. Minimum 5 -year follow-up of anterior column structural allografts in the thoracic and lumbar spine. Spine (Phila Pa 1976) 24:967-972, 1999

26. Pelker RR, Friedlaender GE, Markham TC. Biomechanical properties of bone allografts. Clin Orthop Relat Res:54-57, 1983

27. Przybylski GJ, Sharan AD. Single-stage autogenous bone grafting and internal fixation in the surgical management of pyogenic discitis and vertebral osteomyelitis. J Neurosurg 94:1-7, 2001

28. Rezai AR, Woo HH, Errico TJ, Cooper PR. Contemporary management of spinal osteomyelitis. Neurosurgery 44:10181025; discussion 1025-1016, 1999

29. Roberto T, Daniele M, Martina C, Tiziano de G, Roberto D. Treatment of thoracolumbar spinal infections through anterolateral approaches using expandable titanium mesh cage for spine reconstruction. Scientific World Journal 2012:545-293, 2012

30. Safran O, Rand N, Kaplan L, Sagiv S, Floman Y. Sequential or simultaneous, same-day anterior decompression and posterior stabilization in the management of vertebral osteomyelitis of the lumbar spine. Spine (Phila Pa 1976) 23:1885-1890, 1998

31. Schuster JM, Avellino AM, Mann FA, Girouard AA, Grady MS, Newell DW, et al. Use of structural allografts in spinal osteomyelitis: A review of 47 cases. J Neurosurg 93:8-14, 2000

32. Suess O, Weise L, Brock M, Kombos T. Debridement and spinal instrumentation as a single-stage procedure in bacterial spondylitis/spondylodiscitis. Zentralbl Neurochir 68:123-132, 2007

33. Triantafyllou N, Sotiropoulos E, Triantafyllou JN. The mechanical properties of the lyophylized and irradiated bone grafts. Acta Orthop Belg 41 Suppl 1:35-44, 1975

34. Vaccaro AR, Cirello J. The use of allograft bone and cages in fractures of the cervical, thoracic, and lumbar spine. Clin Orthop Relat Res:19-26, 2002

35. Weigel B, Maghsudi M, Neumann C, Kretschmer R, Muller FJ, Nerlich M. Surgical management of symptomatic spinal metastases. Postoperative outcome and quality of life. Spine (Phila Pa 1976) 24:2240-2246, 1999

36. Wittenberg RH, Moeller J, Shea M, White AA, $3^{\text {rd }}$, Hayes WC. Compressive strength of autologous and allogenous bone grafts for thoracolumbar and cervical spine fusion. Spine (Phila Pa 1976) 15:1073-1078, 1990 